\section{A Comprehensive Arabidopsis Yeast Two-Hybrid Library for Protein-Protein Interaction Studies: A Resource to the Plant Research Community}

\author{
Cleverson Carlos Matiolli and Maeli Melotto ${ }^{\dagger}$ \\ Department of Plant Sciences, University of California, Davis, 95616, U.S.A.
}

\begin{abstract}
Yeast-two-hybrid $(\mathrm{Y} 2 \mathrm{H})$ cDNA library screening is a valuable tool to uncover protein-protein interactions and represents a widely used method to investigate protein function. However, low transcript representation in CDNA libraries limits the depth of the screening. We have developed a Y2H library with cDNA made from Arabidopsis leaves exposed to several stressors as well as untreated leaves. The library was built using pooled mRNA extracted from plants challenged with plant and human bacterial pathogens, the flg22 elicitor, the phytotoxin coronatine, and several hormones associated with environmental stress responses. The purpose of such a library is to maximize the discovery of protein-protein interactions that occur under optimum conditions as well as during biotic and abiotic stresses.
\end{abstract}

Proteins are the basic blocks of signal transduction and biosynthetic pathways as well as the structural components that support life. In the last decades, mounting evidence supports the importance of protein complexes, rather than single proteins, for the regulation of biological processes (Arabidopsis Interactome Mapping Consortium 2011; Kulandaisamy et al. 2017; Spirin and Mirny 2003). Thus, the elucidation of protein-protein interactions that occurs in living organisms is a central aspect in biological research and, along with "omics" approaches, it represents an important step to reach a broader understanding of biological processes.

The yeast-two-hybrid (Y2H) system is an in-vivo approach that uses the Saccharomyces cerevisiae heterologous system to investigate specific pairwise protein interactions and to screen for putative interaction partners among elements of a selected cDNA library (Fields and Sternglanz 1994; Parrish et al. 2006). Briefly, a protein of interest (bait) used to screen the library for putative interactors, is cloned in-frame with a DB (DNA-binding) domain, while the library (prey) is cloned in-frame with a transcription $A D$ (activation domain). The resulting protein fusions are denominated DB-bait and AD-prey, respectively. If the bait protein interacts with prey protein, the DB-bait/AD-prey complex binds to a promoter, thereby activating the transcription of either an enzyme that complements a specific yeast auxotrophy or a reporter that catalyzes the formation of a pigment, allowing detection of bait-prey interaction, using a selective medium or observation of the yeast colony color, respectively.

$\mathrm{Y} 2 \mathrm{H}$ screening represents a powerful and fast approach to identify new putative protein interactions, despite the drawbacks in the utilization of heterologous systems to investigate protein-protein interactions (Koegl and Uetz 2007), and the need for further confirmation of the interaction using other methods, such as coimmunoprecipitation of protein complexes or split fluorescence approaches such as bimolecular fluorescence complementation (Brückner et al. 2009; Walter et al. 2004). However, a common issue in $\mathrm{Y} 2 \mathrm{H}$ screenings is the low

${ }^{\dagger}$ Corresponding author: Maeli Melotto; E-mail: melotto@ucdavis.edu

Accepted for publication 12 March 2018.

This article is in the public domain and not copyrightable. It may be freely reprinted with customary crediting of the source. The American Phytopathological Society, 2018.

\section{Funding}

This work was funded by the National Institute of Food and Agriculture grant CA-D-PLS-2327-H and Coordenação de Aperfeiçoamento de Pessoal de Nível Superior grant BEX:4567/11-0.

\section{Keywords}

protein interaction, screening, Arabidopsis, stress response, leaves, plant hormone, innate immunity 
representativeness of certain transcripts in the cDNA libraries. Some transcripts are present in very low amounts within the total mRNA pool obtained from organisms growing at defined standard conditions. To alleviate this issue, one can normalize the library to either reduce the abundance of highly expressed genes, expose the tissue samples to stresses or chemical treatments, or both to activate the transcription of genes with low basal expression level.

\section{Y2H Library Construction}

We developed a $\mathrm{Y} 2 \mathrm{H}$ cDNA library that represents a useful tool to uncover proteinprotein interactions that occur during plant biotic stress as well as optimum conditions of plant growth. The library was built using mRNA extracted from leaves of Arabidopsis thaliana L. Heyhn. ecotype Col-0 challenged with several stimuli.

Plant material. Arabidopsis thaliana L. Heyhn ecotype Columbia (Col-0) (Arabidopsis Biological Resource Center stock CS60000) was sown in a 1:1:1 mixture of growing medium (Redi-earth plug and seedling mix, Sun Gro), fine vermiculite, and perlite (Hummert International). Plants were grown in controlled environmental conditions $\left(22^{\circ} \mathrm{C}, 60 \% \pm 5 \%\right.$ relative humidity $(\mathrm{RH})$, and 12-h photoperiod under light intensity of $100 \mu \mathrm{mol} \mathrm{m} \mathrm{m}^{-2} \mathrm{~s}^{-1}$ ).

Bacterial inoculations. The plant bacterial pathogen Pseudomonas syringae pv. tomato DC3000, the coronatine deficient $P$. syringae pv. tomato DC3118 (Ma et al. 1991), the human bacterial pathogens Escherichia coli O157:H7 isolate 86-24 (Kendall et al. 2010), and Salmonella enterica serovar Typhimurium SL1344 (Kroupitski et al. 2009) were used to inoculate plants, as described previously (Jacob et al. 2017; Roy et al. 2013). Briefly, four- to five-week old Arabidopsis plants were acclimated overnight under $25^{\circ} \mathrm{C}, 60 \% \pm 5 \% \mathrm{RH}$ and were dip-inoculated into bacteria suspensions $\left(1 \times 10^{8} \mathrm{CFU} / \mathrm{ml}\right) 3 \mathrm{~h}$ after the lights were turned on in the morning. After inoculation, plants were kept in these same conditions for the time periods specified in Table 1. Leaves were harvested, were immediately frozen in liquid $\mathrm{N}_{2}$, and were stored at $-80^{\circ} \mathrm{C}$ for subsequent total RNA extraction.

Chemical treatments. The molecular signals used to induce low abundance transcripts were: i) the phytotoxin coronatine (Sigma Aldrich, St. Louis), a jasmonoyl-L-isoleucine molecular mimicry, deployed by several strains of $P$. syringae (Bender et al. 1999) to overcome plant defenses (Melotto and Kunkel 2013); ii) flg22 (GenScript), a MAMP (microbe associated molecular pattern) with a conserved segment of 22 amino acids present in the bacterial motor protein flagellin, a protein recognized by the Arabidopsis receptor FLS2 (FLAGELLINSENSITIVE 2) triggering the first line of plant defenses recognized as MAMP-triggered immunity (Jones and Dangl 2006; Zipfel et al. 2004); iii) the purified plant hormones salicylic acid (Sigma Aldrich), methyl jasmonate (Sigma Aldrich), and abscisic acid (Sigma Aldrich), which are associated with plant responses to biotic and abiotic stresses. For each chemical treatment, three rosette leaves from the middle-layer of four- to five-week-old Arabidopsis were detached and were immediately submerged in a solution containing the specified chemical for $30 \mathrm{~min}$ (Table 1). The leaves were frozen in liquid $\mathrm{N}_{2}$ and stored at $-80^{\circ} \mathrm{C}$ for subsequent total RNA extraction.

RNA extraction. Approximately $100 \mathrm{mg}$ of frozen Arabidopsis leaves from each treatment (Table 1) were finely ground in liquid $\mathrm{N}_{2}$ and total RNA was extracted using the RNeasy Plant

Table 1. Chemicals and bacterial strains used to induce low abundance transcripts in Arabidopsis plants and subsequent yeast two-hybrid library construction

\begin{tabular}{|c|c|c|c|}
\hline \multirow[b]{2}{*}{ Treatment } & \multirow[b]{2}{*}{ Concentration } & \multicolumn{2}{|r|}{ Treatment } \\
\hline & & Duration & Method \\
\hline $\begin{array}{l}\text { Water } \\
\text { Salicylic acid } \\
\text { Methyl jasmonate } \\
\text { Abscisic acid } \\
\text { Coronatine } \\
\text { flg22 }\end{array}$ & $\begin{array}{c}- \\
20 \mu \mathrm{M} \\
50 \mu \mathrm{M} \\
10 \mu \mathrm{M} \\
10 \mu \mathrm{M} \\
20 \mu \mathrm{M}\end{array}$ & $30 \mathrm{~min}$ & $\begin{array}{l}\text { Submersion of } \\
\text { detached leaves in } \\
\text { chemical solution }\end{array}$ \\
\hline $\begin{array}{l}\text { Pseudomonas syringae pv. tomato } \\
\text { DC3000 }\end{array}$ & $1 \times 10^{8} \mathrm{CFU} / \mathrm{ml}$ & 3 h; 24 h & $\begin{array}{l}\text { Dip-inoculation of rosettes } \\
\text { into bacterial suspension }\end{array}$ \\
\hline $\begin{array}{l}\text { P. syringae pv. tomato DC3118 } \\
\text { Escherichia coli O157: } \mathrm{H} 7 \\
\text { isolate } 86-24\end{array}$ & $\begin{array}{l}1 \times 10^{8} \mathrm{CFU} / \mathrm{ml} \\
1 \times 10^{8} \mathrm{CFU} / \mathrm{ml}\end{array}$ & $\begin{aligned} 3 \mathrm{~h} \\
48 \mathrm{~h}\end{aligned}$ & \\
\hline $\begin{array}{l}\text { Salmonella enterica } \\
\text { Typhimurium SL1344 }\end{array}$ & $1 \times 10^{8} \mathrm{CFU} / \mathrm{ml}$ & $5 \mathrm{~h}$ & \\
\hline
\end{tabular}


Mini Kit (Qiagen), following the manufacturer's instructions. The purity of total RNA samples was assessed by verifying the $260 / 230$ and $260 / 280$ ratios by spectrophotometry (NanoDrop 2000, Thermo Scientific), and RNA integrity and concentration were evaluated by capillary electrophoresis using the Agilent Bioanalyzer 2100 (Plant RNA Pico 6000, Agilent), following the manufacturer's instructions. Total RNAs with an RNA integrity number $>6.7$ were used for the $\mathrm{Y} 2 \mathrm{H}$ library construction.

Library construction. The library construction was performed by Synthetic Biology and Cloning Business, Life Technologies as follows. mRNA was transcribed into cDNA using the kit SuperScript III (Invitrogen) and an oligo-dT primer containing the attB2 recombination site as initiator for the reverse transcription reaction. The resulting cDNA was recombined into the intermediary library vector pENTR 222, using the kit BP Clonase II enzyme mix (Invitrogen), and was transformed into E. coli $\mathrm{DH} 10 \mathrm{~B}-\mathrm{T} 1 \mathrm{R}$ phage-resistant cells. This clone library was subsequently transferred to the $\mathrm{PB} 42 \mathrm{AD}$ attR destination vector by recombination, using the kit LR Clonase II Enzyme Mix (Invitrogen), and was transformed into E. coli DH10B-T1R phage-resistant cells. Plasmid DNA was extracted from this final clone library using the Invitrogen PureLink HiPure Plasmid Midiprep kit (Invitrogen). Thus, the $\mathrm{Y} 2 \mathrm{H}$ library is maintained as E. coli glycerol stock and as plasmid DNA.

\section{Y2H Library Screening Assay}

Full-length or partial coding regions of the protein of interest ('bait') are cloned, using specific primers, into pENTR-D-TOPO (ThermoScientific), following the manufacturer instructions, to generate pENTR-D-TOPO:bait intermediary entry vector. Subsequently, the intermediary entry vector is recombined into yeast expression vector pGILDA (Gimeno et al. 1996), in fusion with LexA DB domain, using LR Clonase II (Invitrogen), following manufacturer instructions. The resulting yeast expression vector pGILDA:bait is transformed into Saccharomyces cerevisiae EGY48 [MATa his3 trp1 ura2 lexAop(x6)-leu2] (Clontech) carrying the vector p8op-lacZ, which contains the lac $Z$ reporter gene under the control of the minimal GAL1 promoter fused to eight upstream operators bound by LexA DB (Clontech). All yeast transformation steps in this protocol are performed using the Frozen EZ yeast transformation II kit (ZymoResearch), following manufacturer's instructions. Yeast transformants are plated on minimal SD (synthetic defined) glucose media plates (Clontech), lacking the uracil (-URA) and histidine (-HIS) auxotrophic markers for p8op-lacZ and pGILDA:bait, respectively.

Positive yeast clones carrying both p8op-lacZ and pGILDA:bait vectors are transformed with 1 to $10 \mu \mathrm{g}$ of the $\mathrm{Y} 2 \mathrm{H}$ cDNA library, which contains a population of representative transcripts obtained from plants treated as listed in Table 1, cloned into PB42AD vector [pB42AD:prey $(n)]$, where $(n)$ represents an unknown putative interactor of bait. The library transformation step must result in a high number of yeast transformants (number of transformants $>10^{7} \mathrm{CFU} / \mathrm{ml}$ ), which are selected by plating the transformed yeast strains onto 10 to 20 large plates of minimal SD glucose media lacking uracil $(-U R A)$, histidine $(-H I S)$, and tryptophan (-TRP). TRP is the auxotrophic marker for pB42AD:prey vector selection. After three to four days of growth, triple yeast transformants are scraped from the plates, are suspended in $1 \times$ TE buffer ( $10 \mathrm{mM}$ Tris- $\mathrm{HCl}, 1 \mathrm{mM}$ EDTA $\left.\cdot \mathrm{Na}_{2}, \mathrm{pH}=8.0\right)$, and are plated onto minimal SD galactose/rafinnose agar media plates (Clontech) containing X-gal (Clontech) and lacking uracil $(-U R A)$, histidine $(-H I S)$, tryptophan $(-T R P)$, and leucine $(-L E U)$. The screening for positive protein-protein interactions using this protocol takes advantage of the EGY48 strain auxotrophy for leucine, which will be produced in yeast containing positive protein-protein interactions through the activation of LEU2 marker gene by the LexA DB-bait/ B42 AD-prey complex.

To minimize false positives, this system also includes the reporter gene lacZin p8op-lacZ vector, which enables selection of putative interactors by the appearance of blue colonies. The reporter gene is activated by the LexA DB-bait/B42 AD-prey complex that binds to the operator driving lacZ transcription. Blue colonies are picked and the putative interactor of the bait is identified by sequencing the pB42AD insert using vector-specific primers.

\section{Validation Of The Library Quality}

To determine the quality of this $\mathrm{Y} 2 \mathrm{H}$ library, we confirmed that the library preparation yielded $2.8 \times 10^{7}$ primary clones, with $95 \%$ of the clones containing an average insert size of 
approximately $1 \mathrm{~kb}$. The expression library plasmid DNA was obtained at a concentration of $3.8 \mu \mathrm{g} / \mu \mathrm{l}$ in a total of $0.5 \mathrm{ml}$. This is a good representation of the total Arabidopsis transcriptome at a given time and indicates the library is of decent quality.

To estimate the representation of stress-associated transcripts in this library, we have performed a Y2H library screening using the Arabidopsis JAZ4 protein (At1g48500) as a bait. We identified four previously reported interactors of JAZ proteins (Zhang et al. 2017) and 22 new putative interactors of JAZ4. Specifically, we pulled out 52 clones from the library, of which one was JAZ3 (At3g17860), two were MYC4 (At4g17880), four were MYC3 (At5g46760), and five were MYC2 (At1g32640). Thus, 23\% of clones are known interactors (12 of 52). This result served as a positive control for the screening and indicated that the library is useful to identify novel interactors of stress-associated baits.

\section{Literature Cited}

Arabidopsis Interactome Mapping Consortium. 2011. Evidence for network evolution in an Arabidopsis interactome map. Science 333:601-607.

Bender, C. L., Alarcón-Chaidez, F., and Gross, D. C. 1999. Pseudomonas syringae phytotoxins: Mode of action, regulation, and biosynthesis by peptide and polyketide synthetases. Microbiol. Mol. Biol. Rev. 63:266-292.

Brückner, A., Polge, C., Lentze, N., Auerbach, D., and Schlattner, U. 2009. Yeast twohybrid, a powerful tool for systems biology. Int. J. Mol. Sci. 10:2763-2788.

Fields, S., and Sternglanz, R. 1994. The two-hybrid system: An assay for proteinprotein interactions. Trends Genet. 10:286-292.

Gimeno, R. E., Espenshade, P., and Kaiser, C. A. 1996. COPII coat subunit interactions: Sec24p and Sec23p bind to adjacent regions of Sec16p. Mol. Biol. Cell 7:1815-1823

Jacob, C., Panchal, S., and Melotto, M. 2017. Surface inoculation and quantification of Pseudomonas syringae population in theArabidopsis leaf apoplast. Bio Protoc. 7:e2167.

Jones, J. D., and Dangl, J. L. 2006. The plant immune system. Nature 444:323-329.

Kendall, M. M., Rasko, D. A., and Sperandio, V. 2010. The LysR-type regulator QseA regulates both characterized and putative virulence genes in enterohaemorrhagic Escherichia coli 0157:H7. Mol. Microbiol. 76:1306-1321.

Koegl, M., and Uetz, P. 2007. Improving yeast two-hybrid screening systems. Brief. Funct. Genomics Proteomics 6:302-312.

Kroupitski, Y., Golberg, D., Belausov, E., Pinto, R., Swartzberg, D., Granot, D., and Sela, S. 2009. Internalization of Salmonella enterica in leaves is induced by light and involves chemotaxis and penetration through open stomata. Appl. Environ. Microbiol. 75:6076-6086.
Kulandaisamy, A., Lathi, V., ViswaPoorani, K., Yugandhar, K., and Gromiha, M. M. 2017. Important amino acid residues involved in folding and binding of proteinprotein complexes. Int. J. Biol. Macromol. 94:438-444.

Ma, S. W., Morris, V. L., and Cuppels, D. A. 1991. Characterization of a DNA region required for production of the phytotoxin coronatine by Pseudomonas syringae pv. tomato. Mol. Plant-Microbe Interact. 4:69-74.

Melotto, M., and Kunkel, B. N. 2013. Virulence strategies of plant pathogenic bacteria. Pages 61-82 in: The Prokaryotes - Prokaryotic Physiology and Biochemistry. 4th Ed. E. Rosenberg, E. Stackebrand, E. F. DeLong, F. Thompson, S. Lory, eds. Springer-Verlag, Berlin.

Parrish, J. R., Gulyas, K. D., and Finley, R. L., Jr. 2006. Yeast two-hybrid contributions to interactome mapping. Curr. Opin. Biotechnol. 17:387-393.

Roy, D., Panchal, S., Rosa, B. A., and Melotto, M. 2013. Escherichia coli 0157:H7 induces stronger plant immunity than Salmonella enterica Typhimurium SL1344. Phytopathology 103:326-332.

Spirin, V., and Mirny, L. A. 2003. Protein complexes and functional modules in molecular networks. Proc. Natl. Acad. Sci. U.S.A. 100:12123-12128.

Walter, M., Chaban, C., Schütze, K., Batistic, O., Weckermann, K., Näke, C., Blazevic, D., Grefen, C., Schumacher, K., Oecking, C., Harter, K., and Kudla, J. 2004. Visualization of protein interactions in living plant cells using bimolecular fluorescence complementation. Plant J. 40:428-438.

Zhang, L., Zhang, F., Melotto, M., Yao, J., and He, S. Y. 2017. Jasmonate signaling and manipulation by pathogens and insects. J. Exp. Bot. 68:1371-1385.

Zipfel, C., Robatzek, S., Navarro, L., Oakeley, E. J., Jones, J. D., Felix, G., and Boller, T. 2004. Bacterial disease resistance in Arabidopsis through flagellin perception. Nature 428:764-767. 